\title{
Numerical investigation of high temperature synthesis gas pre- mixed combustion via ANSYS Fluent
}

\author{
Dmitry Pashchenko * \\ ${ }^{1}$ Samara State Technical University, Russia, 443100 Samara, Molodogvardiyskaya str. 244
}

\begin{abstract}
A numerical model of the synthesis gas pre-mixed combustion is developed. The research was carried out via ANSYS Fluent software. Verification of the numerical results was carried out using experimental data. A visual comparison of the flame contours that obtained by the synthesis gas combustion for $\mathrm{Re}=600 ; 800 ; 1000$ was performed. A comparison of the wall temperature of the combustion chamber, obtained with the help of the developed model, with the results of a physical experiment was also presented. For all cases, good convergence of the results is observed. It is established that a change in the temperature of the syngas/air mixture at the inlet to the combustion chamber does not significantly affect the temperature of the combustion products due to the dissipation of the $\mathrm{H}_{2} \mathrm{O}$ and $\mathrm{CO}_{2}$ molecules. The obtained results are of practical importance for the design of heat engineering plants with thermochemical heat recovery.
\end{abstract}

\section{Introduction}

Energy and environmental problems are the reasons for the constant perfection of energy installations, the search for new fuels, the development of innovative technologies for the use of traditional hydrocarbon fuels, etc. In recent decades, specialists and engineers from different countries have paid much attention to the use of hydrogen as a fuel source of energy. Thus, according to the Hydrogen Scenario of the International Energy Agency (IEA), large-scale hydrogen production on a global scale will increase by $20-25 \%$ annually after 2030 [1]. The main consumers of hydrogen should be transport and power plants using this gas as fuel. Known problems of storage and transportation of hydrogen to consumers stipulate the use of technologies in the transitional stage, in which fuel hydrogen is produced directly on the fuel-consuming installation (on-board hydrogen production) [2].

The production of hydrogen-containing gas immediately before consumption has found application in high-temperature plants (HTP) with thermochemical recuperation of the flue gases heat[4, 5].

The main concept of thermochemical waste-heat recuperation is transfor- mation of flue gases heat into chemical energy of a new synthetic fuel that has higher calorimetric properties such as low heating value. If in the conventional high-temperature plants, for example the industrial furnaces, conversion of chemical energy of fuel into heat energy occurs by fuel combustion, then in the HTP with TCR the conversion of chemical energy of fuel is divided into two stages. The first stage is the increasing of the low heat value of initial fuel by transformation of enthalpy waste-heat into chemical

^e-mail: pashchenkodmitry@mail.ru 
energy of the new synthetic fuel. The second stage is combustion of the new synthetic fuel that has low heat value greater than the low heat value of primary fuel.

In HTP with thermochemical regeneration the hydrogen-containing gas is utilized as fuel at the same HTP [6, 7]. Combustion of synthesis gas of various compositions is a fairly well studied process both experimentally and theoretically. However, the publications in the literature do not cover the entire spectrum of practically interesting questions, in particular, the combustion of high-temperature hydrogen-containing gases in high-temperature plants with thermochemical heat recovery.

The present work is devoted to a numerical study of the characteristics of combustion of synthesis gas that produced in a system of thermochemical heat recuperation. The study was carried out in the software ANSYS Fluent (Academic Research).

\section{Numerical setup}

\subsection{Computational domain}

The schematic diagram of the high-temperature plant with thermochemical heat recuperation of waste flue gases by steam methane reforming is presented in Fig.1.

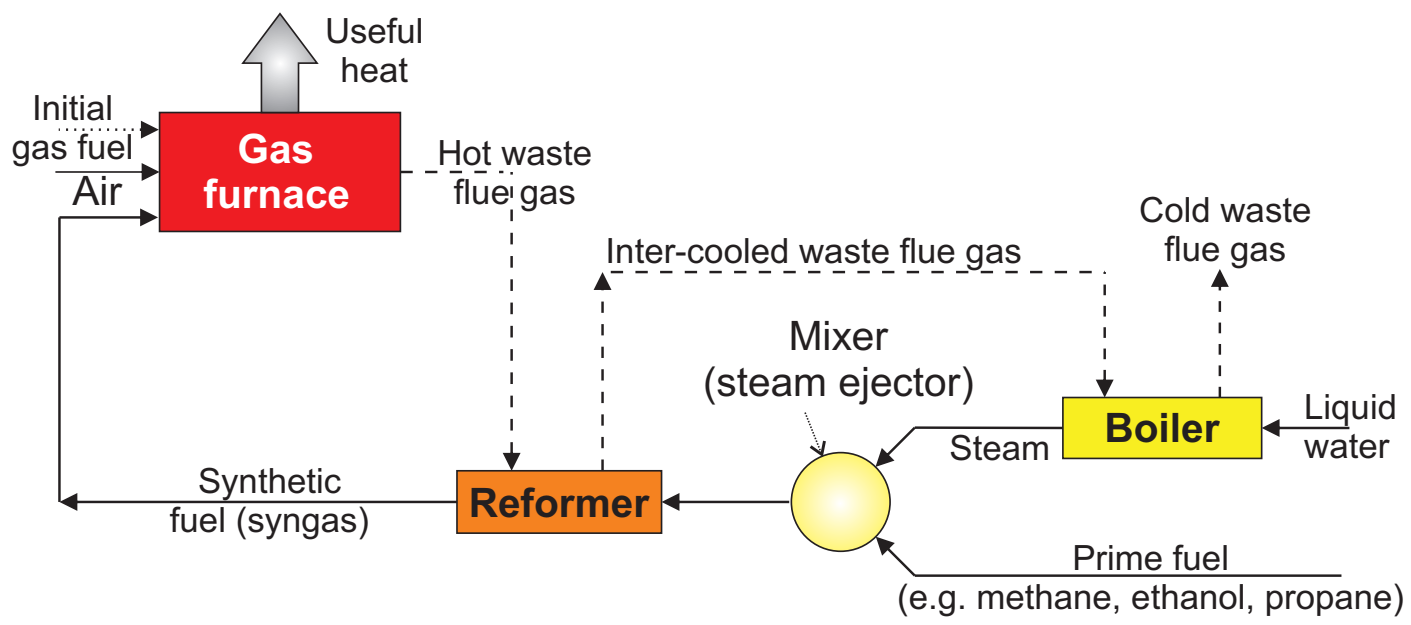

Figure 1. The schematic diagram of high-temperature plant with thermochemical waste-heat recuperation

The overall reaction in steam methane reforming process to form $\mathrm{H}_{2}, \mathrm{C}, \mathrm{CO}, \mathrm{CO}_{2}, \mathrm{H}_{2} \mathrm{O}$ and other components may include the different equations, but the biggest contribution for energy and material balance are follow reactions:

$$
\begin{gathered}
\mathrm{CH}_{4}+\mathrm{H}_{2} \mathrm{O}=\mathrm{CO}+3 \mathrm{H}_{2}-206.2 \mathrm{~kJ} / \mathrm{mol} \\
\mathrm{CO}+\mathrm{H}_{2} \mathrm{O}=\mathrm{CO}_{2}+\mathrm{H}_{2}+41.1 \mathrm{~kJ} / \mathrm{mol} .
\end{gathered}
$$

The composition of the synthesis gas after conversion depends both on the technological parameters of the operation of the thermochemical heat recovery system: the temperature of the flue gases, the composition of the initial reaction mixture, the pressure, and the design characteristics of the reformer: the volume of the reaction space, the catalyst and its amount, 
The composition of the synthesis gas after steam methane reforming process depends both on the technological parameters: the temperature of the flue gases, the composition of the initial reaction mixture, the pressure, and the design characteristics of the reformer: the volume of the reaction space, the catalyst and its amount. The equilibrium composition of the synthesis gas for the $\mathrm{H}_{2} \mathrm{O} / \mathrm{CH}_{4}$ ratio in the initial reaction mixture of 2 is shown in the Table 1 .

Table 1. Synthesis gas composition

\begin{tabular}{cccccc}
\hline Temperature & $\mathrm{H}_{2}$ & $\mathrm{CO}$ & $\mathrm{H}_{2} \mathrm{O}$ & $\mathrm{CO}_{2}$ & $\mathrm{CH}_{4}$ \\
\hline $700 \mathrm{~K}$ & 33.04 & 4.07 & 32.34 & 6.52 & 23.63 \\
$800 \mathrm{~K}$ & 58.11 & 9.86 & 18.94 & 7.23 & 5.86 \\
$900 \mathrm{~K}$ & 61.34 & 12.89 & 16.51 & 6.08 & 3.18 \\
$1000 \mathrm{~K}$ & 63.40 & 14.38 & 16.12 & 5.08 & 1.02 \\
$1100 \mathrm{~K}$ & 63.65 & 16.14 & 16.15 & 3.98 & 0.08 \\
\hline
\end{tabular}

A two dimensional cylindrical combustor model was built and numerically solved by using ANSYS code (Fluent solver). The model combustor, its dimensions and mesh structure are presented in Fig. 2. All dimensions are in millimeters. A wall material is steel.
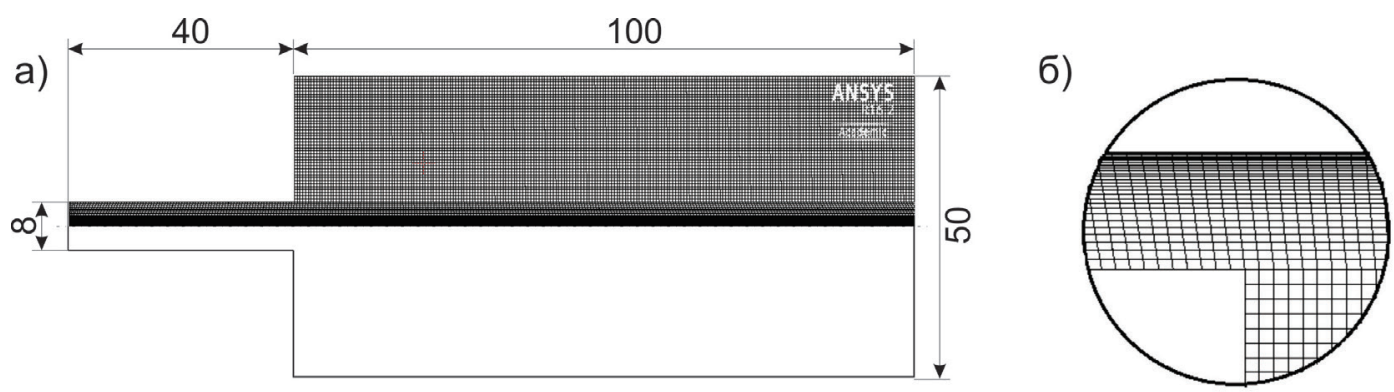

Figure 2. The computational domain and mesh structure of combustor model

\subsection{Mathematical model}

In this paper, syngas with composition according Table 1 used as fuel at stoichiometric conditions and to model combustion process in the combustor, steady state-three-dimensional continuity, energy, momentum and species equations are solved. Following assumptions are made for numerical simulations: steady-state, no energy flux due to mass concentration gradients, no work done by pressure and viscous forces, no gas radiation, no surface reactions and no slip condition at the combustor wall. Combustion reaction scheme was modeled using Eddy Dissipation Concept model.

Continuity equation for steady-state conditions [8]:

$$
\nabla(\rho \cdot u)=0 .
$$

where $u$ is velocity; $\rho$ is density.

$$
\rho(u \cdot \nabla u)=-\nabla p+\nabla\left(\mu \cdot\left[\nabla u+(\nabla u)^{T}-\frac{2}{3} \nabla u \cdot I\right]\right)+\rho \cdot g+F,
$$


where $p$ - pressure; $I$ - unit tensor; $(\nabla u)^{T}$ - the effect of volume dilation; $\rho \cdot g+F$ are the gravitational body force and external body forces.

Energy equation for combustion products:

$$
\nabla u \cdot\left(\rho \cdot E_{f}+p\right)=\nabla\left[k_{e f f} \nabla T-\sum h_{j} \cdot J_{j}+\left(\tau_{e f f} \cdot u\right)\right]+S_{h},
$$

where $k_{\text {eff }}$ is the effective conductivity; $J_{j}$ is the diffusion flux of species $j$; left side of the equation is sum of energy transfer due to conduction, species diffusion, and viscous dissipation, respectively; $S_{h}$ includes the heat of chemical reaction.

Initial and boundary conditions:

- syngas/air inlet: $x=0 ; T_{g}=T_{g(i n)} ; g_{i}=g_{i(i n)}$;

- combustion products outlet: $y=0 ; \frac{\partial g_{i}}{\partial y}=0 ; \frac{\partial T_{g}}{\partial y}=0$;

- combustor wall: $\frac{k_{e f f} \partial^{2} T}{\partial x^{2}}=0 ; \frac{k_{e f f} \partial^{2} T}{\partial y^{2}}=0$.

Here $T_{g}$ is temperature of reaction mixture; $g_{i}$ is mass fraction of $i$ element.

For developed model the standard $k-\epsilon$ model is used. For inlet and outlet of the combustor, mass flow inlet and pressure outlet boundary conditions are employed, where gauge pressure and turbulent intensity of the inlet and outlet are the same (0 Pa and 5\%, respectively) [9].

Calculation method for specific heat and density are incompressible-ideal gas law and mixing law, respectively. Viscosity and gas thermal conductivity of the mixture are calculated by averaging mass fraction of all species. Convergence criteria for momentum, continuity and species are a value of residual less than $10^{-3}$; for energy is $10^{-6}$. All of the equations are discretized by a second-order upwind scheme.

\section{Results and discussion}

\subsection{Model validation}

For verification of the developed model, the experimental combustion data of the fuel mixture of the following composition was used: $\mathrm{CH}_{4}=68 \% ; \mathrm{CO}_{2}=22 \% ; \mathrm{H}_{2}=10 \%$ with complete premixing at equivalence air ratio 1.0 .

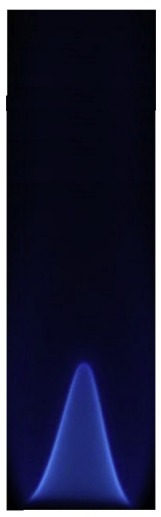

$\operatorname{Re}=600$

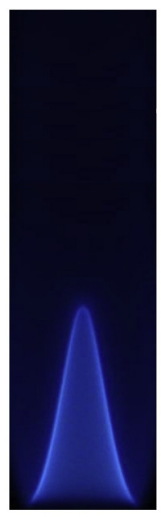

$\mathrm{Re}=800$

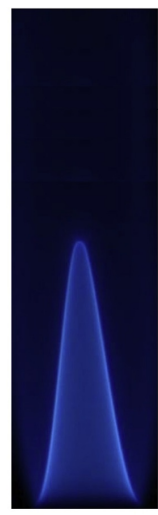

$\mathrm{Re}=1000$
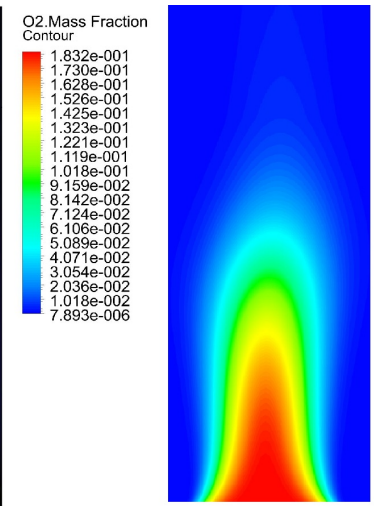

$\mathrm{Re}=600$

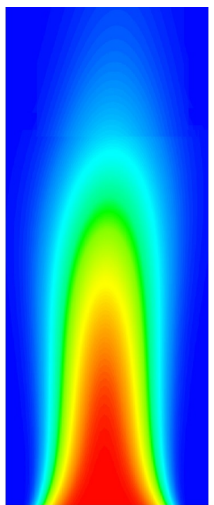

$\mathrm{Re}=800$

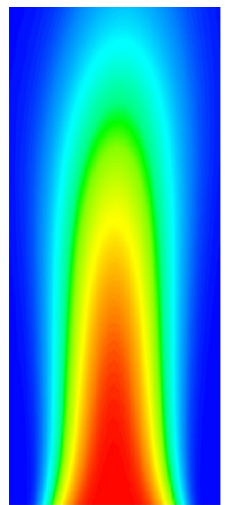

$\operatorname{Re}=1000$

Figure 3. The contours of flame for various Reynolds number 
In Fig. 3 the results of the experiment and the contour of the mass fraction of oxygen obtained as a result of calculations for different values of the Reynolds number are shown. The kinematic viscosity of the gas mixture for determining the Reynolds number is calculated by the Sutherland rule. Visual comparison of flame shows good convergence of the results obtained with the help of the model with experimental data. For simulation results, one can see the characteristic Bunsen cone - the combustion front.
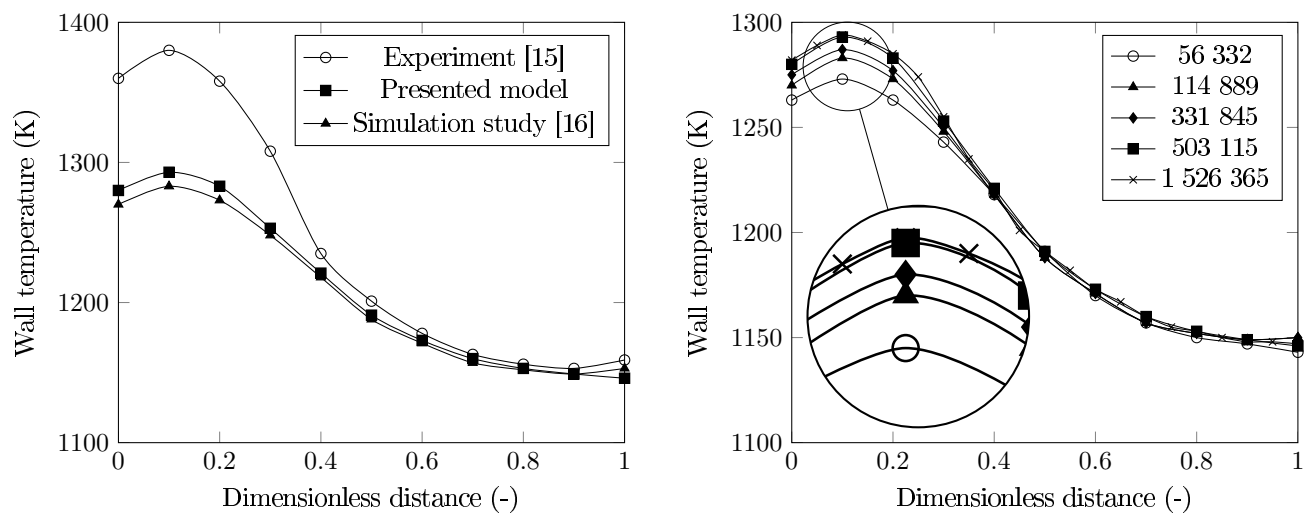

Figure 4. The profile of wall temperature for combustion chamber (left figure) and the Grid independency study (right figure)

To validate developed model additionally, calculated wall temperature were compared with experimental results of Yang and co-workers [59] and modeling investigation of Jiaqiang and co-authors [53]. As presented in Fig. 4, the agreement between results is well. Discrepancies between experimental data and simulation results may be seen at the zone close to inlet of the combustor. These discrepancies can be as the results of errors of the experimental setup and assumptions for the mathematical model. However, these discrepancies slow down towards the midsection of the combustor chamber and calculated wall temperature profiles show a good agreement with experimental results in terms of trend and value. Towards the outlet of the combustor, discrepancies become apparent again. Boundary conditions: Hydrogen flow rate and equivalence ratio are $5.25 \times 10^{-7} \mathrm{~kg} / \mathrm{s}$ and 1.0 , respectively, the mass flow rate of the inlet is $1.8551 \times 10^{-5} \mathrm{~kg} / \mathrm{s}$; both side walls are adiabatic.

\subsection{Grid independency study}

In numerical modeling of fluid dynamics, the accuracy of the results is determined not only by the solver setup and the specified convergence criteria, but also by the number of unit cells and the quality of the mesh $[17,18]$. In this study, the minimum number of cells for the computational domain shown in Fig. 2 is estimated. Calculations are made for the following initial data: fuel - $100 \%$ hydrogen; Hydrogen flow rate and equivalence ratio are $5.25 \times 10^{-7} \mathrm{~kg} / \mathrm{s}$ and 1.0 , respectively so mass flow rate of the inlet is $1.8551 \times 10^{-5} \mathrm{~kg} / \mathrm{s}$; both side walls are adiabatic. The number of cells varied from 56 332 to 1526365 with the constant convergence criteria mentioned above.

From Fig. 4 (right side) it is seen that with increasing number of cells, the accuracy of calculation increases. However, with an increase in the number of cells greater than 500,000, the results change insignificantly. Therefore, for further calculations, the number of cells is recommended to be selected 
in the range from 500 to 600 thousand. In this case, a satisfactory quality of the results is observed with a minimum of processing power.

\subsection{Combustion products temperature and contours}

In Fig. 5 shows the distribution of the combustion products temperature for synthesis gas of various compositions and the temperature given in the Table 1. The number of cells for computational domain is 503 115. The calculations were carried out for the equivalence air ratio 1.0. The obtained dependences make it possible to state that the composition and temperature of the synthesis gas of the parameters under study do not have a significant effect on the temperature of the combustion products. This can be explained by the dissociation of molecules of water and carbon dioxide, which is accompanied by the absorption of heat generated as a result of combustion of fuel. Such a strong effect of dissociation on the heat balance can be explained by the large amount of physical heat introduced with the fuel-air mixture and the minimum excess pressure in the combustion chamber.

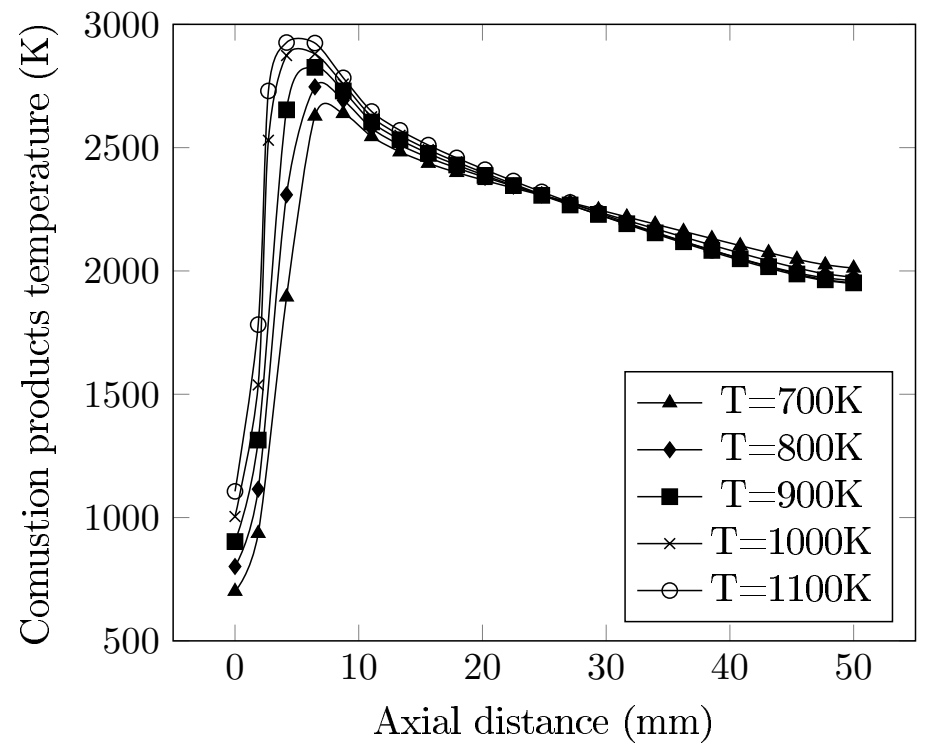

Figure 5. The profile of combustion products temperature along axial distance of combustion chamber

The results in Fig. 5 can be used to design combustion chambers for high-temperature plants with thermochemical heat recovery. Also, the results show that when the HTP is transferred for thermochemical recuperation of heat, it is necessary to take into account the change in the temperature regime of such an installation. The temperature in the combustion chamber can be controlled by recirculating the flue gases after the steam generator (Fig. 1).

In Fig. 6 shows the contours of temperature (a), velocity (b), turbulent viscosity (c), and mass fraction of oxygen (d) in the combustion chamber. The composition of synthesis gas obtained at the methane conversion process temperature of $900 \mathrm{~K}$ and at an equivalence air ratio of 1.0. The presented contours give a graphic representation of the processes occurring during the combustion of the fuel-air mixture. 

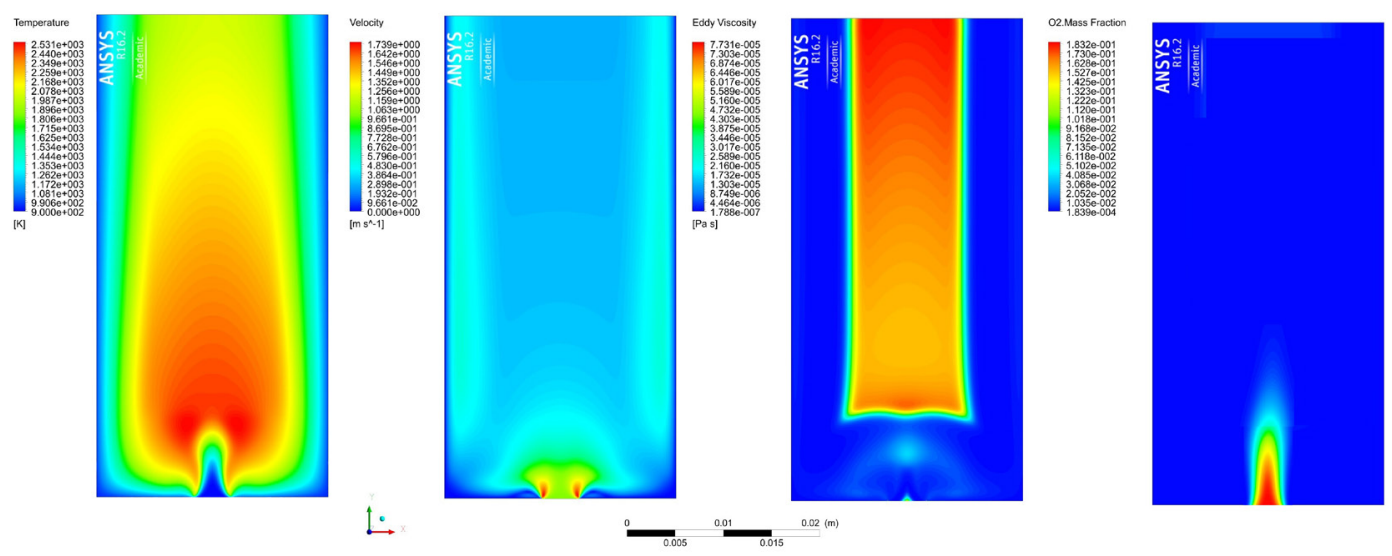

Figure 6. The profile of combustion products temperature along axial distance of combustion chamber

\section{Conclusion}

The developed numerical model of the syngas/air combustion makes it possible to determine the thermal characteristics of the process at each point of the combustor. With the help of the model it is established that an increase in the temperature of the fuel-air mixture before combustion does not lead to a significant change in the temperature regime in the combustion chamber. For all investigated fuel compositions, the temperature of the combustion products at the combustor outlet is about $2000 \mathrm{~K}$. Numerical results have good convergence with experimental data. Thus, the root-mean-square deviation of the results of the wall temperature of the combustion chamber, obtained with the help of the model, in comparison with the experimental data for all computational domain does not exceed 0.036. In addition, for the verification of the developed model, experimental combustion data of the fuel mixture of the following composition were used: $\mathrm{CH}_{4}=68 \% ; \mathrm{CO}_{2}=22 \% ; \mathrm{H}_{2}=10 \%$ with complete premixing at $\alpha=1.0$. Visual comparison of physical and numerical flames shows good convergence of the results obtained with the help of the model with experimental data. For simulation results, a cone of Bunsen - the combustion front, is seen.

It has been established that an increase in the number of elementary cells for the investigated computational domain is more than 500-600 thousand does not lead to a noticeable increase in the accuracy of the results. A commercial software ANSYS Fluent with a particular choice of several physical models (regarding turbulence, combustion, radiation) is used for this analysis. The obtained data can be used in the design of heat engineering plants with thermochemical regeneration of the heat of the exhaust flue gases due to steam methane conversion.

\section{References}

[1] Soria A., Szabo L., Russ P., Suwala W., World Energy Technology Outlook 2050 (European Commission. Joint Research Center. 2006) 221.

[2] Chakravarthy V. K., Daw C.S., Pihl J.A., Conklin J.C., Energy\&Fuels 24(3), 1529-1537 (2010).

[3] Popov S. K., Svistunov I.N., Garyaev A.B., Serikov E.A., Energy 127, 44-51 (2017).

[4] Pashchenko D. I., Thermal Engineering 60(6),438-443 (2013).

[5] Verkhivker G., Kravchenko V., Energy 29(3), 379-388 (2004). 
[6] Pashchenko D., International Journal of Hydrogen Energy 42(22), 14926-14935 (2017).

[7] Zarov E. A., Kul'kov M. G., Filippov I. V., Water Resources. 44(2), 267-275 (2017).

[8] Tsynaeva A. A., Nikitin M. N., Procedia Engineering. 150, 2340-2344 (2017).

[9] Tsynaeva A., Nikitin M., MATEC Web of Conferences. 86, 04-018 (2017). 